\title{
Editorial
}

\section{Karl Rickels: A Tribute on His 90th Birthday}

\section{Per Bech}

Psychiatric Research Unit, Psychiatric Centre North Zealand, Copenhagen University Hospital, Hillerød, Denmark

\section{Introduction}

In his 2011 autobiography, A Serendipitous Life [1], Karl Rickels describes how in 2008 in Munich at the 50th anniversary of the Collegium Internationale NeuroPharmacologicum (CINP) he looked around at the President's Dinner, '... a special event held in the Emperor's Hall at the residence of Bavaria's famous king. I saw only one person I remembered from the first congress in Rome. I had been one of the younger biological psychiatrists in 1958, so this wasn't a surprise ...'

I was attending the same dinner, and while we were waiting for the doors to open at this 2008 President's Dinner I actually had a good long talk with Karl Rickels. I told him that in 1982 I had participated in Aaron Beck's workshop on cognitive therapy for depression. It was held in Philadelphia on the premises of Beck's Center for Cognitive Therapy that was situated (around Room 602) on the same floor where Karl Rickels' Division of Psychopharmacology was also situated (around Room 402). I asked Karl whether he and Aaron Beck were both still working there at the University of Philadelphia, and he told me that this was indeed the case.

Since 1959 Beck and Rickels had worked at the University of Pennsylvania and as good colleagues treated outpatients suffering from neurotic depression and neurotic anxiety [2]. They had both drawn the conclusion

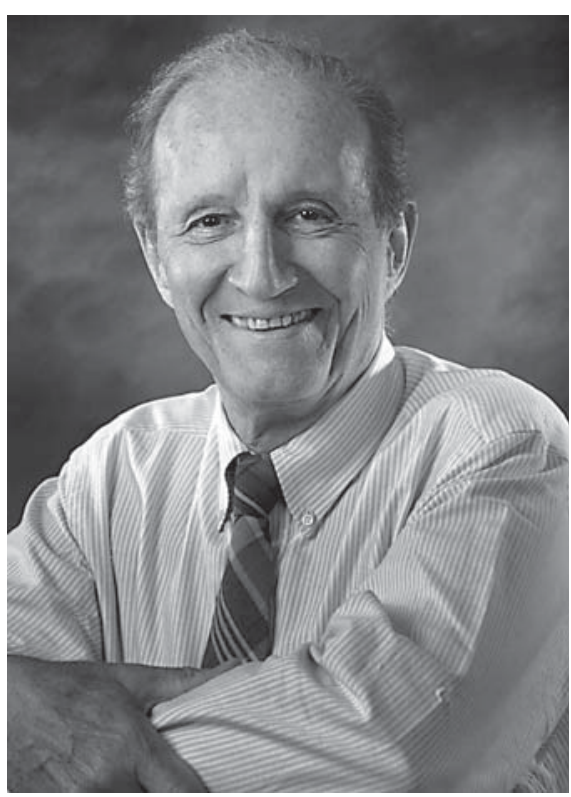

Karl Rickels, MD.

that psychoanalysis, the main form of therapy for these patients in the 1950s, had no effect and they both found it important to adhere to measurement-based therapy. Beck had done so with his Beck Depression Inventory since 1961 [3], while Rickels used the Hopkins Symptom

\section{KARGER}

E-Mail karger@karger.com www.karger.com/pps (c) 2014 S. Karger AG, Basel

0033-3190/14/0833-0131\$39.50/0 
Checklist (HSCL) that was published in 1954 by Jerry Frank and his Baltimore group [4]. Later on Rickels and Lipman adapted the HSCL for the assessment of depression and the various anxiety states (interpersonal sensitivity, generalized anxiety, panic, social phobia and OCD). As clinician-administered outcome measures they both used the Hamilton Scales for the assessment of anxiety and depression. However, their initial interest differed. Rickels was especially focused on anxiety neurosis since 1959, whereas Beck's first interest was depressive neurosis.

\section{Anxiolytics (Tranquilizers)}

In 1959 Rickels conducted the first placebo-controlled study with meprobomate in patients with anxiety disorders [5]. A year later he completed a placebo-controlled study with chlordiazepoxide (Librium), and presented his findings at a congress in Mexico City in 1960. After diazepam, the most potent benzodiazepine, became available in 1963, Rickels used it as an active reference drug in placebo-controlled trials with new anti-anxiety agents such as buspirone and pregabalin.

In 1993 Rickels and his group demonstrated in a placebo-controlled trial with imipramine (using diazepam as an active reference) that imipramine was superior to diazepam on the core items of anxiety in the Hamilton Anxiety Scale. They found both drugs far superior to placebo [6].

In the 1990s selective serotonin reuptake inhibitors (SSRIs) became available and Rickels and his group could now demonstrate that paroxetine was significantly better than placebo in patients with the DSM-IV diagnosis of generalized anxiety disorder. When testing the specific serotonin and noradrenaline reuptake inhibitor venlafaxine, Rickels and his group could also demonstrate the drug's superiority to placebo in generalized anxiety disorder [7].

\section{Panic Attacks: Freud's Mixed Model ('gemischte Neurose')}

When describing anxiety neurosis as a psychoneurosis in 1895 Freud considered 'free-floating anxiety' to include excessive worrying and persistent apprehension which might increase into anxiety attacks [8] (see also Rickels and Rynn [9]). Freud observed that anxiety neurosis commonly occurred together with obsessive-com- pulsive states. As noticed by Healy in 1993 [10], panic disorder, agoraphobia and obsessive-compulsive states are clearly associated with each other, whereas hysteria and the dissociation states are not.

After Klein [11] had shown that imipramine was very effective in treating panic attacks (soon confirmed by others) he was invited by Robert Spitzer to become a member of the DSM-III Task Force on anxiety disorders.

The story of the term 'panic' is that Klein consulted Joan Riviere's edition of Freud's work where the term 'Anfall von Angst' became 'panic' instead of 'anxiety attacks' [12]. Spitzer introduced inclusion and exclusion criteria for the different psychiatric diagnoses and because neurosis seemed only to be an exclusion criterion he found the diagnostic category of panic disorder useful, especially because Spitzer himself had some clinical experience in this area [12].

After the introduction of SSRIs, Rickels suggested abandoning diagnoses and just calling depression, panic, generalized anxiety, social phobia and OCD SSRI-responsive states. In the study of Downing and Rickels [13] on mixed anxiety - facts and myths, it was shown by use of the HSCL-90 that patients with predominant anxiety scores had received benzodiazepines from their clinicians and patients with the highest scores on the depressive items had received amitriptyline. In this way Rickels advocates adhering to a measurement-based therapy where the relative scores on an HSCL-90-like questionnaire as regards depression versus anxiety should be the treatment guideline rather than a specific diagnosis.

\section{The Hopkins Symptom Checklist (HSCL-90)}

The first version of the HSCL consisted of 41 items [4, 14] covering the general distress dimension that patients were complaining of when attending the University of Baltimore psychotherapeutic outpatient clinic headed by Frank [15]. This dimension of distress included items for depression, anxiety and interpersonal sensitivity. Over the years the HSCL was enlarged to become the HSCL-90 $[16,17]$. In this enlargement of the scale Rickels played a major role [1] in the inclusion of specific anxiety items for panic disorder, obsessive-compulsive states and social phobia. The HSCL-90 is one of the most widely used patient-completed rating scales in the world, as stated by Rickels in his 2011 autobiography [1]; thus, the paper by Derogatis et al. [18] in which it was published in 1973 has been cited approximately 3,500 times. 
As pointed out by Frank [19] in his collection of studies using questionnaires or rating scales for the measurement of neurotic symptoms and general neurotic behaviour, the studies by Rickels and his group are among the very few that have selectively focused on 'true' neurosis. In the other studies the only 'guarantee' we have is that the patients are classified as 'not psychotic'.

Since 1964 Rickels has systematically used the HSCL scale in his drug trials of anxiolytics [20, 21]. In 1972 he advocated the use of the HSCL as outcome measure in trials with anxiolytics in the sense that the score has to be within the limits of the general population as the goal of treatment. This approach has now been adopted in health-related quality of life trials [22].

\section{The University of Pennsylvania Private Practice Research Group}

Before the rise of psychopharmacology in the 1950s, an annotation about psychotherapy in general practice in England [23] stated that the time at the practitioner's disposal was so limited that the advice was to focus on the patient's emotional sufferings rather than the physical ones when physical symptoms persist without any clear somatic abnormalities. Comorbid mental health problems still constitute a significant element in the workload of general practitioners [24] and they are often managed by the family doctors without referral to other services [25]. In England Balint introduced training groups for general practitioners in the 1950s and 1960s in the use of a psychodynamic approach for neurotic disorders [26].

It should be noted that it was Rickels and not Beck who developed a shared care model in Philadelphia between the university Department of Psychiatry and local family doctors for measurement-based therapy of depression and anxiety. In the early 1960s Rickels built a Private Practice Research Group [27] to conduct clinical trials outside his Department of Psychopharmacology in Philadelphia. Each family doctor practice was considered as one individual centre of research and each doctor had to contribute approximately 20 patients in a multi-centre trial. This construction was unique compared to all other multi-centre trials in anxiety and depression in North America, Canada or Europe. In England a trial in the family doctor setting was organized so that up to 80 general practitioners each contributed 1 or 2 patients. In Denmark, with the advent of the DSM-III, we investigated the effect of a benzodiazepine, bromazepam, in the family doctor setting in patients with generalized anxiety disor-

Karl Rickels: A Tribute on His 90th Birthday der. We trained 57 family doctors in the use of the Hamilton Anxiety Scale but only 38 of them provided patients and the median number of patients per doctor was 5 , ranging from 1 to 29 [28].

Therefore, the Philadelphia-based Private Practice Research Network created by Rickels is quite unique. It is also important because psychotherapeutic drugs need to be evaluated within those treatment settings in which they are most commonly employed.

When I visited Beck's department in Philadelphia in 1982, Karl Rickels was on his summer vacation, but a research assistant in the Department of Psychopharmacology, Norman Norstad, gave me a copy of the rater training form. In their publication, Rickels et al. [29] state that all the physicians participating in the trial were members of the University of Philadelphia Private Practice Research Group and that each of them had been trained in conducting clinical research, and the group's research activities were supervised and monitored throughout the study. Each week, the physicians scored the Hamilton Rating Scales for anxiety and depression, while the patients completed the HSCL-90. Ever since I first read Rickels' instruction guide for his research physicians, it has been a guide for my own research as well. For example, in the case of the Hamilton Depression Scale I was inspired by the way Rickels had modified the item definitions for the family doctor setting. Furthermore, when recruiting patients the physicians were asked to evaluate whether the patient expected psychiatric drug treatment for his or her condition and whether the physician felt that drug treatment was the most suitable option for each particular patient. The physician also had to evaluate whether the patient suffered from any predominant personality disorder and whether the patient was basically an introvert or an extrovert. The inter-rater reliability of video-taped Hamilton Anxiety Scale interviews has been obtained in the group of participating family doctors (intraclass coefficients of 0.79 ) [27].

\section{Discontinuation Symptoms of Benzodiazepine versus Antidepressants}

Because of cross-tolerance between alcohol and benzodiazepine the use of benzodiazepines in terms of a dependence syndrome in patients with persistent anxiety disorder has been intensely discussed. Rickels et al. [30] have shown that approximately $40 \%$ of the patients who had received diazepam continuously for more than 8 months developed withdrawal symptoms upon abrupt discontin- 
uation. Reviewing studies in patients who had been treated with antidepressants (from clomipramine to paroxetine) for a period of 6-8 months covering the expected duration of a depressive episode, it was found that approximately $30 \%$ experienced physical and cognitive symptoms [31]. The difference in the underlying pharmacology of the benzodiazepine withdrawal reaction and the antidepressant withdrawal reaction is evident. Thus, there is no cross-tolerance between benzodiazepines and antidepressants. A potentially fatal full-blown alcohol withdrawal syndrome can be treated with benzodiazepines but it is definitely a medical error to use paroxetine or venlafaxine in this situation. Increased pulse and severe motor restlessness are among the most prevalent alcohol withdrawal symptoms, but it is the increased temperature (hyperthermia) that is the fatal reaction [14]. When comparing the severity of withdrawal reaction as regards benzodiazepines versus antidepressants, it is these fatal symptoms that should be taken into consideration.

In a recent editorial in this journal Rickels asks: 'Should benzodiazepines be replaced by antidepressants in the treatment of anxiety disorders?' [32]. Concerning the findings in the meta-analysis by Offidani et al. [33], Rickels says that we have no evidence for the superiority of paroxetine or venlafaxine over benzodiazepines in generalized anxiety disorder, either in terms of efficacy or safety. As suggested by Rickels, a direct comparison between, for example, venlafaxine and diazepam in patients with anxiety disorders without depression is certainly needed [32].

In his autobiography Rickels writes: 'I was asked once why I never saw this benzodiazepine dependence phenomenon in my private patients. I realized then that I was trained in medical school to prescribe medication under the following guidelines: increase slowly, attempt to get best results with as low a daily dose as possible, and always discontinue slowly. Thus, I always tapered my patients in the use of benzodiazepines ...' [1]. When SSRIs were in- troduced, the companies marketing these drugs suggested that the drugs be prescribed without monitoring blood concentration, in contrast to the tricyclic antidepressants. However, the guidelines Rickels has followed are also highly valid when prescribing SSRIs. Increase slowly, go for the minimal needed dose and always taper the patients slowly. Reading Rickels' publications, and especially those that deal with the controversies between benzodiazepines and antidepressants, we are listening to the experienced psychiatrist who, like the good family doctor, has a holistic approach based on medicine as a science as well as an art.

\section{Conclusion}

Measurement-based treatment has played a key role in Karl Rickels' success as a research psychopharmacologist. Specifically, I strongly believe that one of the reasons why Rickels has been able to maintain an active research group of family doctors in Philadelphia is that he has invited the group for bi-yearly training sessions at his department. These gatherings are not used exclusively to establish inter-rater reliability, but also to have an ongoing discussion on various procedural and methodological aspects of conducting clinical trials. In this long-lasting research process he has constantly been able to help the family doctor to become more sensitive to what is going on in the doctor-patient relationship with the very mixed symptoms of psychic and somatic anxiety.

At the latest CINP Congress in Stockholm in 2012 Karl Rickels received the CINP award 'Pioneers in Psychopharmacology'. He received his award for his measurement-based treatment of patients with 'gemischter Neurose', showing that psychotherapeutic drugs have to be tested in the general practice setting where these patients, so correctly described by Freud, have to be treated.

\section{References}

1 Rickels K: A Serendipitous Life: from German POW to American Psychiatrist. Evergreen, Notting Hill Press, 2011.

2 Healy D: Karl Rickels interviewed by David Healy; in Levine J (ed): Psychopharmacology. CreateSpace Independent Publishing Platform, 2011, vol 4, pp 333-342.

- 3 Beck AT, Ward CH, Mendelson M, Mock J, Erbaugh J: An inventory for measuring depression. Arch Gen Psychiatry 1961;4:561571.
4 Parloff MB, Kelman HC, Frank JD: Comfort, effectiveness, and self-awareness as criteria of improvement in psychotherapy. Am J Psychiatry 1954;111:343-351.

5 Rickels K, Clark TW, Ewing JH, Klingensmith WC, Morris HM, Smock CD: Evaluation of tranquilizing drugs in medical outpatients: meprobomate, prochlorperazine, amobarbital sodium, and placebo. J Am Med Assoc 1959;171:1656.
6 Rickels K, Downing R, Schweizer E, Hassman $\mathrm{H}$ : Antidepressants for the treatment of generalized anxiety disorder. A placebo-controlled comparison of imipramine, trazodone, and diazepam. Arch Gen Psychiatry 1993; 50:884-895.

7 Rickels K, Mangano R, Khan A: A doubleblind, placebo-controlled study of a flexible dose of venlafaxine ER in adult outpatients with generalized social anxiety disorder. J Clin Psychopharmacol 2004;24:488-496. 
8 Freud S: Über die Berechtigung, von der Neurasthenie einen bestimmten Symptomenkomplex als 'Angstneurose' abzutrennen. Neurol Zentralbl 1895;14:50-66.

$>9$ Rickels K, Rynn M: Overview and clinical presentation of generalized anxiety disorder. Psychiatr Clin North Am 2001;24:1-17.

10 Healy D: Images of Trauma: from Hysteria to Post-Traumatic Stress Disorder. London, Faber \& Faber, 1993.

$>11$ Klein DF: Delineation of two drug-responsive anxiety syndromes. Psychopharmacologia 1964;5:397-408.

12 Healy D: The Psychopharmacologists. London, Chapman \& Hall, 1996.

13 Downing RW, Rickels K: Mixed anxiety-depression: fact or myth? Arch Gen Psychiatry 1974;30:312-317.

14 Bech P: Rating Scales for Psychopathology, Health Status and Quality of Life. A Compendium on Documentation in Accordance with the DSM-III-R and WHO Systems. Berlin, Springer, 1993.

15 Frank JD: Persuasion and Healing. Baltimore, Johns Hopkins University Press, 1961.

16 Lipman RS, Covi L, Shapiro AK: The Hopkins Symptom Checklist (HSCL) - factors derived from the HSCL-90. J Affect Disord 1979;1: 9-24.

17 Lipman RS: Depression scales derived from the Hopkins Symptom Checklist; in Sartorius N, Ban T (eds): Assessment of Depression. Berlin, Springer, 1986, pp 232-248.
18 Derogatis LR, Lipman RS, Covi L: SCL-90: an outpatient psychiatric rating scale - preliminary report. Psychopharmacol Bull 1973;9: 13-28.

19 Frank G: Psychiatric Diagnosis: a Review of Research. Oxford, Pergamon Press, 1975.

20 Rickels K: The use of psychotherapy with drugs in the treatment of anxiety. Psychosomatics 1964;5:111-115.

21 Rickels K, Downing RW: Drug- and placebotreated neurotic outpatients. Pretreatment levels of manifest anxiety, clinical improvement, and side reactions. Arch Gen Psychiatry 1967;16:269-272.

22 Bech P: Clinical Psychometrics. Oxford, Wiley Blackwell, 2012.

23 Anonymous: Psychotherapy in general practice. Lancet 1939;233:707-708.

24 Üstün TB, Sartorius N: Mental Illness in General Health Care. Chichester, John Wiley, 1995.

25 Goldberg D: Epidemiology of mental disorders in primary care settings. Epidemiol Rev 1995; 17:182-190.

26 Williamson JD: Balint's contribution to general practice. J R Coll Gen Pract 1978;28:207209.
27 Rickels K, Hesbacher P, Fisher EL, Norstad N: The Private Practice Research Group (PPRG): a working model from psychopharmacology for clinical research in family practice. J Clin Pharmacol 1977; 17:541-554.

28 Kragh-Sorensen P, Holm P, Fynboe C, Schaumburg E, Andersen B, Bech P, Pichard $\mathrm{J}$ : Bromazepam in generalized anxiety. Randomized, multi-practice comparisons with both chlorprothixene and placebo. Psychopharmacology (Berl) 1990;100:383-386.

29 Rickels K, Weisman K, Norstad N, Singer M, Stoltz D, Brown A, Danton J: Buspirone and diazepam in anxiety: a controlled study. J Clin Psychiatry 1982;43:81-86.

30 Rickels K, Schweizer E, Case WR: Withdrawal problems with anti-anxiety drugs: nature and management; in Tyrer P (ed): Psychopharmacology of Anxiety. Oxford, Oxford University Press, 1989, pp 283-292.

31 Fava GA, Offidani E: The mechanisms of tolerance in antidepressant action. Prog Neuropsychopharmacol Biol Psychiatry 2011;35: 1593-1602.

32 Rickels K: Should benzodiazepines be replaced by antidepressants in the treatment of anxiety disorders? Fact or fiction? Psychother Psychosom 2013;82:351-352.

>33 Offidani E, Guidi J, Tomba E, Fava GA: Efficacy and tolerability of benzodiazepines versus antidepressants in anxiety disorders: a systematic review and meta-analysis. Psychother Psychosom 2013;82:355-362. 